\title{
3-D Seismic Experimentation and Advanced Processing/Inversion Development for Investigations of the Shallow Subsurface
}

\author{
Levander, Alan R. \\ Rice University
}

RESULTS TO DATE: Gian Fradelizio, a Rice Ph.D. student has completed reprocessing the 3D seismic reflection data acquired at Hill AFB through post-stack depth migration for comparison to the traveltime and waveform tomography results.

Zelt, Levander, Fradelizio, and 5 others spent a week at Hill AFB in September 2005, acquiring an elastic wave data set along 2 profiles. We used 60 3-component Galperin mounted $40 \mathrm{~Hz}$ geophones recorded by 3 GEOMETRICS Stratavision systems. The seismic source employed was a sledehammer used to generate transverse, and radial, and vertical point source data. Data processing has begun at Rice to generate S-wave reflection and refraction images. We also acquired surface wave and ground penetrating rada data to complement the elastic wave dataset.

DELIVERABLES: Gao, F., A. Levander,G. Pratt, C.A. Zelt, and G. Fradelizio, 2005, Waveform tomography at a groundwater contamination site, Geophysics, in press.

Fuchun Gao, Gian Luigi Fradelizio, Alan Levander and Colin Zelt, 2005. High Resolution Waveform Tomography at a Ground Water Contamination Site. IRIS "One-Pager". Contribution to IRIS proposal.

Gao, F., A. Levander, R.G. Pratt, C.A. Zelt, and G-L. Fradelizio, 2005, Waveform tomography at a groundwater contamination site: Surface reflection data, submitted to Geophysics, 24 August, 2005.

Zelt, C.A., A. Azaria, and A. Levander, 2005, 3-D seismic refraction tomography at a groundwater contamination site, submitted to Geophysics, October, 2005.

F. Gao, G.-L. Fradelizio, A. Levander, G. Pratt, C.A. Zelt, 2005, Seismic Velocity, Q, Geological Structure and Lithology Estimation at a Ground Water Contamination Site, SEG Expanded Abstract, to be presented November 2005.

G.-L. Fradelizio, F. Gao, A. Levander, C.A. Zelt, 2005, Shallow Structures Characterization at a Groundwater Contamination Site: Seismic Processing and Tomographic Inversion, to be presented at the Fall 2005 AGU Meeting. 